Portland State University

PDXScholar

Institute for Sustainable Solutions Publications and Presentations

11-1-1996

\title{
Ecological economics: reintegrating the study of humans and nature
}

Robert Costanza

Portland State University

Follow this and additional works at: https://pdxscholar.library.pdx.edu/iss_pub

Part of the Sustainability Commons

Let us know how access to this document benefits you.

Citation Details

Costanza, R. 1996. Ecological economics: reintegrating the study of humans and nature. Ecological Applications 6:978-990.

This Article is brought to you for free and open access. It has been accepted for inclusion in Institute for Sustainable Solutions Publications and Presentations by an authorized administrator of PDXScholar. Please contact us if we can make this document more accessible: pdxscholar@pdx.edu. 


\title{
ECOLOGICAL ECONOMICS: REINTEGRATING THE STUDY OF HUMANS AND NATURE ${ }^{1,2}$
}

\author{
ROBERT COSTANZA \\ University of Maryland Institute for Ecological Economics, Center for Environmental and Estuarine Studies, \\ Box 38, Solomons, Maryland 20688-0038 USA, and \\ Zoology Department, University of Maryland, College Park, Maryland 20742
}

\begin{abstract}
Ecological economics is a transdisciplinary effort to link the natural and social sciences broadly, and especially ecology and economics. The goal is to develop a deeper understanding of the complex linkages between ecological and economic systems, and to use that understanding to develop effective policies that will lead to a world that is ecologically sustainable, has a fair distribution of resources (both among groups and generations of humans and between humans and other species), and efficiently allocates scarce resources including "natural capital." This will require new approaches that are comprehensive, adaptive, integrative, multi-scale, and pluralistic, and that acknowledge the huge uncertainties involved. Examples of integrated assessment and modeling studies at local, regional, and global scales are discussed as cases that both require and force the integration of ecology and economics and help to build common understanding of linked ecologicaleconomic systems.
\end{abstract}

Key words: aggregation error; cultural vs. genetic evolution; ecological economics; ecological sustainability; hierarchy of scales; history of ecology; models, conceptual vs. analytic; modeling as a consensus-building tool; modeling complex systems; natural capital.

\section{ECOLOGY AND THE ECONOMY OF NATURE}

Ernst Heinrich Haeckel (1834-1919) was the first to use the word "oecologie," in 1866. In 1870 he produced the first full-fledged definition of "ecology":

By ecology we mean the body of knowledge concerning the economy of nature-the investigation of the total relations of the animal both to its inorganic and to its organic environment including above all, its friendly and inimical relations with those animals and plants with which it comes directly or indirectly into contact-in a word, ecology is the study of all those complex interrelations referred to by Darwin as the conditions of the struggle for existence.

(Translation in Allee et al. 1949)

Thus even in this initial definition of the field, a deep conceptual relationship with economics is evident Ecology was, in Haeckel's words, the study of the economy of nature. Economics, conversely, can be thought of as the ecology of humans, with a particular emphasis on how we manage our affairs. But historically the science of ecology evolved out of biology and ethology (the science of animal behavior) and thus had very different intellectual roots from economics. In practical terms, ecology became the study of the economy of that part of nature that does not include humans.

\footnotetext{
${ }^{1}$ Manuscript received 20 December 1994; revised 10 July 1995; accepted 8 November 1995; final version received 11 January 1996.

${ }^{2}$ For reprints of this group of papers, see footnote 1, p.
}

Since Haeckel's early definition, many other definitions of ecology emerged based on changing areas of interest and emphasis (McIntosh 1985). When there was a focus on animal populations, ecology was "the study of the distribution and abundance of animals" (Andrewartha and Birch 1954). Later, when ecosystems became a major focus, ecology was "the study of the structure and function of ecosystems" (E. P. Odum 1971). But what has remained at the core is the relationship of organisms to their environment. As one of the dominant species of animals on the planet, Homo sapiens and its relationship to its environment is obviously well within the scope of ecology by any of its various definitions.

From the very beginnings of ecology as a science there have been continuing attempts to incorporate humans and the social sciences. The work of H. T. Odum (1971), Meadows et al. (1972), Holling (1978), Walters (1986), and many others is certainly in this tradition. While these attempts have been very influential (and often controversial), the vast majority of ecologists continue to ignore humans in their day-to-day research. One might ask why ecologists were not persistent or effective enough in their attempts to extend ecological thinking to Homo sapiens.

Likewise in economics and the other social sciences there is a history of attempts to bring the natural world back into the picture (Hardesty 1977, Harris 1979, Dunlap 1980, Boulding 1981), but the dominant tendency has been to consider humans to be somehow outside the laws and constraints that applied to other animals and to study humans in relative isolation from the rest of nature. 
This fragmentation of science into separate, isolated disciplines is a late 19 th- and early 20 th-century phenomenon. Before that time there was significant interaction among all aspects of science, and one could say that science was practiced in a "transdisciplinary" way (Costanza et al. 1997). But by the end of the 19th century the trend to increasing specialization and professionalization in science, including economics and the other social sciences, was well under way (Coats 1993).

What has come to be called the "reductionist" paradigm was beginning to hold sway. This paradigm assumes that the world is separable into relatively isolated units that can be studied and understood on their own, and then reassembled to give a picture of the whole. As the complexity of science increased, this was a very useful idea, since it allowed dividing up the problem into smaller, more manageable pieces that could be attacked intensively. Chemists could study chemistry without being distracted by other aspects of the systems they were studying. Also, the rapid increase in the sheer number of scientists who were actively working made it necessary to organize the work in some way, and the disciplinary structure seemed a logical and useful way to do this. But once university departments were set up in the various disciplines, internal reinforcement systems came to reward only work in the discipline. This rapidly led to a reduction in communication across disciplines and a tendency for the disciplines to develop their own unique languages, cultures, and ways of looking at the world. Disciplinary speciation through isolation had begun to occur.

In economics, this led to a growing isolation from the natural resource (or land) component of the classical triad of land, labor, and capital, and with it a growing isolation from the natural sciences. Economics departments began to reward theory more highly than applications, and the discipline as a whole attempted to pattern itself on physics, which was arguably the most successful example of the advantages of the disciplinary model of organization.

This trend continued in the early through middle 20th century and, by the time of the renewed environmental awareness of the 1970s, economics had become highly specialized and abstracted away from its earlier connections with the natural environment. Textbooks at the time barely mentioned the environment and concentrated instead on the microeconomics of supply, demand, and price formation and the macroeconomics of growth in manufactured capital and gross national product (GNP).

At the same time, economics was becoming absorbed with professionalization. As A. W. Coats (1993:27) noted:

At least since the marginal revolution of the 1870's, mainstream economists have sought to enhance their intellectual authority and autonomy by excluding certain questions which were either sensitive (such as the distribution of income and wealth, and the role of economic power in society) or incapable of being handled by their preferred methods and techniques, or both. These are precisely the questions which are emphasized by their professional and lay critics and, more recently, by many economists who cannot be dismissed by their professional colleagues as either ignorant or incompetent.

The story in ecology was somewhat different. As we have previously noted, ecology is a much younger science, and it has always been more explicitly pluralistic and interdisciplinary. But its roots were in biology and the trend in biology was much the same as in other areas of science. The initial split into botany and zoology was followed by further specialization into biochemistry, biophysics, molecular biology, etc. In ecology itself there was something of a split between the population ecologists (e.g., Robert MacArthur) who concentrated on individual populations of organisms, and systems ecologists (e.g., E. P. and H. T. Odum) who focused on whole ecosystems. But this split never got to the point of separation into distinct departments and disciplines, although many academic programs took on a decided flavor in one direction or the other.

Through all of this, ecologists, more so than any other discipline, have maintained communication across most of the natural sciences. To study ecosystems, one has to integrate hydrology, soil science, geology, climatology, chemistry, botany, zoology, genetics, and many other disciplines. The dividing line for many ecologists has been at a particular species, Homo sapiens. Even though Haeckel's original definition at least implicitly included humans, and many ecologists over the years have argued and worked to make this integration operational, for the vast majority of active ecologists the study of humans is outside their discipline, left to the social sciences. Indeed, most ecologists have looked for field sites as remote from human activities as possible to conduct their research.

As McIntosh (1985:319) points out:

If human factors are beyond ecological consideration, what, then is human ecology? It is not clear whether ecology will expand to encompass the social sciences and develop as a metascience of ecology. The alternative is a more effective interdisciplinary relationship between ecology and the several social sciences.

Ecological economics can be seen as an attempt to build this more effective interdisciplinary relationship as a bridge to a truly comprehensive science of humans as a component of nature that will fulfill the early goals of ecology. It is an attempt to help rectify the tendency to ignore humans in ecology, while at the same time rectifying the parallel tendency to ignore the natural world in the social sciences. 
REINTEGRATING ECOLOGY AND ECONOMICS FOR SUSTAINABILITY

Ecology and economics have been separate disciplines throughout their recent histories in the 20th century. While each has certainly borrowed theoretical concepts from the other and shared patterns of thinking from the other sciences, they have addressed separate issues, utilized different assumptions to reach answers, and supported different interests in the policy process. Recognition of the importance of bringing these domains of thought together and attempting to reintegrate the natural and social sciences has lead to what we have been calling "ecological economics." After numerous experiments with joint meetings between economists and ecologists, the International Society for Ecological Economics (ISEE) was formed in 1988, the journal Ecological Economics was initiated and published its first issue in February of 1989 (currently publishing 12 issues per year), and major international conferences of ecologists and economists have been held ever since. Several ecological-economics institutes have been formed around the world, and a significant number of books have appeared with the term "ecological economics" in their titles (e.g., Martinez-Alier 1987, Costanza 1991, Peet 1992, Barbier et al. 1994, Jansson et al. 1994, Krishnan et al. 1995).

Ecological economics is not a single new paradigm based in shared assumptions and theory. It represents a commitment among economists, ecologists, and other academics and practitioners to learn from each other, to explore new patterns of thinking together, and to facilitate the derivation and implementation of new economic and environmental policies. To date, ecological economics has been deliberately conceptually pluralistic even while particular members may prefer one paradigm over another (Norgaard 1989).

To achieve sustainability, the global community must deal with new types of problems threatening the future well-being and existence of Homo sapiens. These problems are fundamentally cross-scale, transcultural, and transdisciplinary, calling for innovative research approaches and new social institutions (Costanza and Daly 1987, Common and Perrings 1992, Berkes and Folke 1994, d'Arge 1994, Holling 1994). This research needs to be integrated with rather than divorced from the policy and management process (Golley 1994, Viederman 1994). Ecological economics addresses the relationships between ecosystems and economic systems in the broadest sense, in order to develop a deep understanding of the entire system of humans and nature as a basis for effective policies for sustainability (Costanza et al. 1991). It takes a holistic "systems" approach that goes beyond the normal boundaries of the academic disciplines. This does not imply that disciplinary approaches are rejected, or that the purpose is to create a new discipline. Ecological economics is interdisciplinary in the sense that scholars from various disciplines collaborate side by side using their own tools and techniques, and transdisciplinary in the sense that new theory, tools, and techniques are developed out of the dialogue to effectively deal with sustainability. It focuses more directly on the problems facing Homo sapiens and the ecosystems on which we depend in the longer term. These problems involve:

1) assessing and ensuring that the scale of human activities within the biosphere is ecologically sustainable;

2) distributing resources and property rights fairly, both within the current generation of humans and between this and future generations, and also between humans and other species; and

3 ) efficiently allocating resources as constrained and defined by (1) and (2) above, and including both marketed and non-marketed resources, especially ecosystems.

Humans have a special role to play because we are responsible for understanding our owil role in the larger system and managing it for sustainability (Costanza et al. 1991). This responsibility is not only an ethical and a moral issue. Sustaining the environment means saving ourselves, including future generations, since we are dependent on healthy ecosystems for survival. Thus, ecological economics is an anthropocentric field of study in the sense that it is concerned about the survival and well-being of Homo sapiens on this planet. It is at the same time biocentric in the sense that it is concerned about the survival and well-being of all other life as well (Rapport 1993).

Ecological economics views the socioeconomic system as a part of the overall ecosphere, emphasizing carrying capacity and scale issues in relation to the growth of the human population and its activities, and the development of fair systems of property rights and wealth distribution.

Uncertainty is recognized as a fundamental characteristic of complex systems, and particular processes in nature are essentially irreversible (Costanza and Cornwell 1992, Ludwig et al. 1993, Clark and Munro 1994, Costanza 1994). Instead of locking ourselves into development paths that may ultimately lead to ecological collapse, we need to conserve and invest in natural capital (Costanza and Daly 1992), in the sense of keeping our ecological life-support systems and interrelated socioeconomic systems resilient to change (Hammer et al. 1993, Holling 1994, Jansson and Jansson 1994, Perrings 1994). Hence, ecological economics has an explicit concern for future generations and long-term sustainability, and works with a broader range of values than the limited perceptions of the current generation of humans (although these perceptions are certainly not ignored). Ethics and equity issues are explored, as well as differences and similarities between worldviews and cultures (Berkes and Folke 1994, Turner et al. 1994). 


\section{INTEGRATED ECOLOGICAL-ECONOMIC MODELING}

One key research area in ecological economics is understanding and modeling the dynamics of linked ecological and economic systems, ranging in size from the biosphere as a whole to regional landscapes to local systems. Integrated ecological-economic systems have so far received only very limited direct scientific attention. Several current approaches may be relevant to this problem, and a cooperative synthesis among ecologists, economists, mathematicians, computer scientists, and many others is essential. I briefly describe general issues of scale and hierarchy in modeling integrated ecological-economic systems along with some ongoing case studies that attempt to implement this approach.

New understanding about system dynamics and predictability that has emerged from the study of "complex systems" is creating new tools for modeling interactions between human and natural systems. A range of techniques has become available through advances in computer speed and accessibility, and by implementing a broad, interdisciplinary systems view.

"Systems" are groups of interacting, interdependent parts linked together by exchanges of energy, matter, and information. "Complex systems" are characterized by: (1) strong (usually nonlinear) interactions among the parts; (2) complex feedback loops that make it difficult to distinguish cause from effect; (3) significant time and space lags; discontinuities, thresholds and limits; all resulting in (4) the inability to simply "addup" or aggregate small-scale behavior to arrive at large-scale results (von Bertalanffy 1968, Rastetter et al. 1992). Ecological and economic systems both independently exhibit these characteristics of complex systems. Taken together, linked ecological-economic systems are devilishly complex.

While almost any subdivision of the universe can be thought of as a "system," modelers of systems usually look for boundaries that minimize the interaction between the system under study and the rest of the universe in order to make their job easier. The interactions between ecological and economic systems are many and strong. So, while splitting the world into separate economic and ecological systems is possible, it does not minimize interactions and is a poor choice of boundary.

Classical (or reductionist) scientific disciplines tend to dissect their subject into smaller and smaller isolated parts in an effort to reduce the problem to its essential elements. In order to allow the dissection of system components, it must be assumed that interactions and feedbacks between system elements are negligible or that the links are essentially linear so they can be added up to give the behavior of the whole (von Bertalanffy 1968). Complex systems violate the assumptions of reductionist techniques and therefore are not well un- derstood using the perspective of classical science. In contrast, "systems analysis" is the scientific method applied across many disciplines, scales, resolutions, and system types in an integrative manner.

In economics, for example, a typical distinction is made between partial equilibrium analysis and general equilibrium analysis. In partial equilibrium analysis, a subsystem (a single market) is studied with the underlying assumption that there are no important feedback loops from other markets. In general equilibrium analysis, on the other hand, the totality of markets is studied in order to bring out the general interdependence in the economy. The large-scale, whole-economy, general equilibrium effects are usually quite different from the sum of the constituent small-scale, partial equilibrium effects. Add to this the further complication that in reality "equilibrium" is never achieved, and one can begin to see the limitations of classical, reductionist science in understanding complex systems.

Economic and ecological analysis needs to shift away from implicit assumptions that eliminate links within and between economic and natural systems, because, due to the strength of the real-world interactions among these components, failing to link them can cause severe misperceptions and indeed policy failures (Costanza 1987). Since reductionist thinking fails in the quest to understand complex systems, new concepts and methods must be devised.

To achieve a comprehensive understanding that is useful for modeling and prediction of linked ecological-economic systems requires the synthesis and integration of several different conceptual frames (Norgaard 1989). As Levins (1966) has described this search for robustness:

we attempt to treat the same problem with several alternative models each with different simplifications . . . Then, if these models, despite their different assumptions, lead to similar results we have what we call a robust theorem which is relatively free of the details of the model. Hence our truth is the intersection of independent lies.

Existing modeling approaches can be classified according to a number of criteria, including scale, resolution, generality, realism, and precision. The most useful approach within this spectrum of characteristics depends on the specific goals of the modeling exercise. I next describe a few examples of how one might match model characteristics with several of the possible modeling goals relevant for ecological economic systems. A better appreciation of the range of possible model characteristics and goals can help to more optimally match characteristics and goals.

Analysis of complex systems offers great potential for generating insights into the behavior of linked ecological-economic systems. These insights will be needed to change the behavior of the human population towards a sustainable pattern, a pattern that works in 
synergy with the life-supporting ecosystems on which it depends. The next step in the evolution of ecological economic models is to fully integrate the two fields and not just transfer methods between them. Clark's (1976, $1981,1985)$ bioeconomics work was the start of this recognition of the importance of linking the mutually interacting sub-parts. But much work remains to be done to bring the two fields and the technology that supports them to the point where their models can adequately interact. Transdisciplinary collaboration and cooperative synthesis among natural and social scientists and others will be essential (Norgaard 1989).

\section{Purposes of models}

Models are analogous to maps. Like maps, they have many possible purposes and uses and no one map or model is right for the entire range of uses (Levins 1966, Robinson 1991). It is inappropriate to think of models or maps as anything but crude (but in many cases absolutely essential) abstract representations of complex territory, whose usefulness can best be judged by their ability to help solve the navigational problems faced. Models are essential for policy evaluation, but are often also misused since there is ". . . the tendency to use such models as a means of legitimizing rather than informing policy decisions. By cloaking a policy decision in the ostensibly neutral aura of scientific forecasting, policy-makers can deflect attention from the normative nature of that decision ..." (Robinson 1992).

In the case of modeling ecological economic systems, purposes can range from developing simple conceptual models, in order to provide a general understanding of system behavior, to detailed realistic applications aimed at evaluating specific policy proposals. It is inappropriate to judge this whole range of models by the same criteria. At a minimum, the three criteria of realism (simulating system behavior in a qualitatively realistic way), precision (simulating behavior in a quantitatively precise way), and generality (representing a broad range of systems' behaviors with the same model) are necessary. Holling (1964) first described the fundamental trade-offs in modeling among these three criteria. Later Holling (1966) and Levins (1966) expanded and further applied this classification. No single model can maximize all three of these goals, and the choice of which objectives to pursue depends on the fundamental purposes of the model. Several examples in the literature of ecological and economic models demonstrate the various ways in which trade-offs are made between realism, precision, and generality.

High-generality conceptual models.-In striving for generality, models must give up some realism and/or precision. They can do this by simplifying relationships and/or reducing resolution. Simple linear and nonlinear economic and ecological models tend to have high generality but low realism and low precision (Clark and
Munro 1975, Brown and Swierzbinski 1985, Kaitala and Pohjola 1988, Lines 1989, 1990). Examples include Holling's "4-box" model (Holling 1987), the "ecological economy" model of Brown and Roughgarden (1992), most conceptual macroeconomic models (Keynes 1936, Lucas 1975), economic-growth models (Solow 1956), and the "evolutionary games" approach. For example, the "ecological economy" model of Brown and Roughgarden (1992) contains only three state variables (labor, capital, and "natural resources") and the relationships among these variables are highly idealized. But the purpose of the model was not high realism or precision, but rather to address some basic, general questions about the limits of economic systems in the context of their dependence on an ecological life-support base.

A different trade-off is achieved in the General Ecosystem Model (GEM) developed by Fitz et al. (1996). This model is intended to be applicable to a whole range of ecosystems and scales, while maintaining a fairly high degree of complexity (20 state variables) and the ability to be used as a module in spatially explicit landscape models (discussed below). Here, some generality is exchanged for increased realism and precision.

High-precision analytical models.-Often, one wants high precision (quantitative correspondence between data and model) and is willing to sacrifice realism and generality. One strategy here is to keep resolution high, but to simplify relationships and deal with short time frames. Some models strive to strike a balance between mechanistic small-scale models that trace small fluctuations in a system and more general wholesystem approaches that remove some of the noise from the signal but do not allow the modeler to trace the source of system changes. The alternative some ecologists have devised is to identify one or a few properties that characterize the system as a whole (Wulff and Ulanowicz 1989). For example, Hannon and Joiris (1987) used an economic input-output model to examine relationships between biotic and abiotic stocks in a marine ecosystem and found that this method allowed them to show the direct and indirect connection of any species to any other and to the external environment in this system at high precision (but low generality and realism). Also using input-output techniques, Duchin's $(1988,1992)$ aim was to direct development of industrial production systems to efficiently reduce and recycle waste, in the manner of ecological systems. Large econometric models (Klein 1971) used for predicting short-run behavior of the economy belong to this class of models since they are constructed to fit existing data as closely as possible (at the sacrifice of generality and realism).

High-realism impact-analysis models.-When the goal is to develop realistic assessments of the behavior of specific complex systems, generality and precision must be relaxed. High-realism models are concerned 
with accurately representing the underlying processes in a specific system, rather than precisely matching quantitative behavior or being generally applicable. Dynamic, nonlinear, evolutionary systems models at moderate to high resolution generally fall into this category. Coastal physical-biological-chemical models (Wroblewski and Hofmann 1989), which are used to investigate nutrient fluxes and contain large amounts of site-specific data, fall into this category, as do micro models of behavior of particular business activities. Another example is Costanza et al.'s (1990) model of coastal landscape dynamics that included high spatial and temporal resolution and complex, nonlinear, process dynamics. This model divided a coastal landscape into $1-\mathrm{km}^{2}$ cells, each of which contained a processbased, dynamic, ecological simulation model. Flows of water, sediments, nutrients, and biomass from cell to cell across the landscape were linked with internal ecosystem dynamics to simulate long-term successional processes and responses to various human impacts in a very realistic way. But the model was very site-specific and of only moderate numerical precision.

Further extensions of this general approach in the Everglades (H. C. Fitz, R. Costanza, and E. Reyes; unpublished report [1993; The Everglades Model, Task 2 Summary] to the South Florida Water Management District, West Palm Beach Florida, USA) and the Patuxent River Basin in Maryland (Bockstael et al. 1995) have demonstrated the utility of simulating the spatially explicit evolution of complex regional ecological systems using a landscape perspective. Economic components are being developed for the Patuxent model to reflect human behavior and economic influences (Bockstael et al. 1995). The effects of human intervention result directly from the conversion of land from one use to another (e.g., wetlands conversion, residential development, power-plant siting) or from changes in the practices that take place within specific land uses (e.g., adoption of agricultural best management practices, intensification of congestion and automobile emissions, change in urban water and sewer use, and storm runoff). Integrated regional models that can address the interactions between humans and the environment with a fairly high degree of realism are becoming quite popular (Groffman and Likens 1994). To address these impacts in a realistic way, which is essential for many policy purposes, generality and precision must be relaxed.

Moderate-generality and moderate-precision indicator models.-In many types of systems modeling, the desired outcome is to accurately determine the overall magnitude and direction of change, trading off realism for some moderate amount of generality and precision. For example, aggregate measures of system performance such as standard GNP, environmentally adjusted net national product (or "green NNP") that includes environmental costs (Mäler 1991), and indicators of ecosystem health (Costanza et al. 1992) fit into this category. The microcosm systems employed by Taub (1989) allow some standardization for testing ecosystem responses and developing ecosystem-performance indices. Taub (1987) notes, however, that many existing indicators of change in ecosystems are based on implicit ecological assumptions that have not been critically tested, either for their generality, realism, or precision.

\section{Complex systems, scale, and hierarchy}

In modeling complex systems, the issues of scale and hierarchy are central (O'Neill et al. 1989, Holling 1992). Some claim that the natural world, the human species included, contains a convenient hierarchy of scales based on interaction-minimizing boundariesscales ranging from atoms to molecules to cells to organs to organisms to populations to communities to ecosystems (including economic, and/or human-dominated ecosystems) to bioregions to the global system and beyond (Allan and Starr 1982, O'Neill et al. 1986). By studying the similarities of and differences between different kinds of systems at different scales and resolutions, one might develop hypotheses and test them against other systems to explore their degree of generality and predictability.

The term "scale" in this context refers to both the resolution (spatial grain size, time step, or degree of complication of the model) and the extent (in time, space, and number of components modeled) of the analysis. The process of "scaling" refers to the application of information or models developed at one scale to problems at other scales. In both ecology and economics, primary information and measurements are generally collected at relatively small scales (e.g., small plots in ecology, individuals or single firms in economics) and that information is then often used to build models at radically different scales (e.g., regional, national, or global). The process of scaling is directly tied to the problem of aggregation, (the process of adding or otherwise combining components) which in complex, nonlinear, discontinuous systems (like ecological and economic systems) is far from a trivial problem (O'Neill and Rust 1979, Rastetter et al. 1992).

For example, in applied economics, basic data sets are usually derived from the national accounts, which contain data that are linearly aggregated over individuals, companies, or organizations. Sonnenschein (1974) and Debreu (1974) have shown that, unless one makes very strong and unrealistic assumptions about the individual units, the aggregate (large-scale) relations between variables have no resemblance to the corresponding relations on the smaller scale.

Rastetter et al. (1992) describe and compare three basic methods for scaling that are applicable to complex systems. All of their methods are attempts to utilize information about the nonlinear small-scale variability in the large-scale models. They list three methods: (1) partial transformations of the fine-scale math- 
ematical relationships to coarse-scale using a statistical-expectations operator that incorporates the fine-scale variability; (2) partitioning or subdividing the system into smaller, more homogeneous parts (i.e., spatially explicit modeling); and (3) calibration of the fine-scale relationships to coarse-scale data, when this data is available. They go on to suggest a combination of these methods as the most effective overall method of scaling in complex systems.

A primary reason for aggregation error in scaling complex systems is the nonlinear variability in the finescale phenomenon. For example, Rastetter et al. (1992) give a detailed example of scaling a relationship for individual leaf photosynthesis as a function of radiation and leaf efficiency to estimate the productivity of the entire forest canopy. Because of nonlinear variability in the way individual leaves process light energy, one cannot simply use the fine-scale relationships among photosynthesis, radiation, and efficiency along with the average values for the entire forest to get total forest productivity without introducing significant aggregation error. One must somehow understand and incorporate this nonlinear fine-scale variability into the coarse-scale equations using some combination of the three methods mentioned above. Method 1 (statistical expectations) implies deriving new coarse-scale equations that incorporate the fine-scale variability. The problem is that incorporation of this variability often leads to equations that are extremely complex and cumbersome (Rastetter et al. 1992). Method 2 (partitioning) implies subdividing the forest into many relatively more homogeneous levels or zones and applying the basic fine-scale equations for each partition. This requires a method for adjusting the parameters for each partition, a choice of the number of partitions (the resolution), and an understanding of the effects of the choice of resolution and parameters on the results. Both spatially explicit models and individual-based models are examples of this method. Method 3 (recalibration) implies simply recalibrating the fine-scale equations to coarse-scale data. It presupposes that coarse-scale data are available (as more than simply the aggregation of fine-scale data). In many important cases, however, this coarse-scale data is either extremely limited or is not available. Thus, while a judicious application of all three aggregation methods is necessary, from the perspective of complex systems modeling, the partitioning approach (Method 2) seems to hold particular promise, because it can take fullest advantage of emerging computer technologies and data bases.

From the scaling perspective, hierarchy theory is a potentially useful tool for partitioning systems in ways that minimize aggregation error. According to hierarchy theory, nature can be partitioned into "naturally occurring" levels that share similar time and space scales, and that interact with higher and lower levels in systematic ways. Each level in the hierarchy sees the higher levels as constraints and the lower levels as noise. For example, individual organisms see the ecosystem they inhabit as a slowly changing set of constraints and the operation of their component cells and organs is what matters most to them. However, Norton and Ulanowicz (1992) suggest that what appears to be "noise" at a lower level could be turned into significant perturbations on the higher level. This can happen when a critical mass of components participate in a "trend," a behavioral pattern that affects the slower processes at the higher level. The rapid and extensive human uses of fossil fuels could be seen as such a trend, causing perturbations at the global atmospheric level, which might feed back and radically alter the framework of action at the lower level.

Shugart (1989) explains the relationship between scales:

Clearly, natural patterns in environmental constraints contribute substantially to the spatial pattern and temporal dynamics of particular ecosystems . . . these patterns, especially temporal ones, may resonate with natural frequencies of plant growth forms (i.e., phenology and longevity) to amplify environmental patterns. The simplifying assumptions of hierarchy theory may ease the problem of scaling by providing a common (but somewhat generalized) set of rules that could be applied at any scale in the hierarchy.

To test some of these ideas, we have recently established a Multiscale Experimental Ecosystem Research Center (MEERC) at the University of Maryland. This Center will construct a series of "cosms" at several time, space, and complexity scales and carry out an integrated experimental and modeling research program aimed at understanding and modeling ecosystems at each of these scales (from microcosms to mesocosms to small and large regional watersheds [macrocosms]). MEERC is focused on assessing the response of these systems to nutrient and toxicant perturbations, and how (and why) these responses change with scale. The ultimate goal is to develop and test a set of performance (health) indicators for these systems, and to develop and test a set of scaling principles that will allow the extrapolation of results across scales. Detailed, dynamic simulation models of all the experimental systems will be developed and the program's experimental design will allow the models to be rigorously tested and calibrated.

\section{Evolutionary approaches}

In modeling the dynamics of complex systems it is impossible to ignore the discontinuities and surprises that often characterize these systems and the fact that they operate far from equilibrium in a state of constant adaptation to changing conditions (Lines 1990, Holland and Miller 1991, Kay 1991, Rosser 1991, 1992). The paradigm of evolution has been broadly applied to both ecological and economic systems (Boulding 1981, Ar- 
thur 1988, Lindgren 1991, Maxwell and Costanza 1993) as a way of formalizing understanding of adaptation and learning behaviors in non-equilibrium dynamic complex systems. The general evolutionary paradigm posits a mechanism for adaptation and learning in complex systems at any scale using three basic interacting processes: (1) information storage and transmission; (2) generation of new alternatives; and (3) selection of superior alternatives according to some performance criteria.

The evolutionary paradigm is different from the conventional optimization paradigm popular in economics in at least four important respects (Arthur 1988): (1) evolution is path dependent, meaning that the detailed history and dynamics of the system are important; (2) evolution can achieve multiple equilibria; (3) there is no guarantee that optimal efficiency or any other optimal performance will be achieved, due in part to path dependence and sensitivity to perturbations; and (4) "lock-in" (survival of the first rather than survival of the fittest) is possible under conditions of increasing returns. While, as Arthur (1988) notes, "conventional economic theory is built largely on the assumption of diminishing returns on the margin (local negative feedbacks)," life itself can be characterized as a positive feedback, self-reinforcing, autocatalytic process (Kay 1991, Günther and Folke 1993) and we should expect increasing returns, lock-in, path dependence, multiple equilibria, and sub-optimal efficiency to be the rule rather than the exception in economic and ecological systems.

Cultural vs. genetic evolution.-In biological evolution, the information-storage medium is the genes, the generation of new alternatives is by sexual recombination or genetic mutation, and selection is performed by nature according to a criteria of "fitness" based on reproductive success. The same process of change occurs in ecological, economic, and cultural systems, but the elements on which the process works are different (Boyd and Richardson 1985). For example, in cultural evolution: (1) the storage medium is the culture-the oral tradition, books, film, or other storage media for passing on behavioral norms and belief systems; (2) the generation of new alternatives is through innovation by individual members or groups in the culture; and (3) selection is again based on the reproductive success of the alternatives generated, but reproduction is carried out by the spread and copying of the behavior or ideas through learning and imitation rather than biological reproduction. One may also talk of "economic" evolution, a subset of cultural evolution dealing with the generation, storage, and selection of alternative ways of producing things and allocating that which is produced. The field of "evolutionary economics" has grown up in the last decade or so based on these ideas (cf. Day and Groves 1975, Day 1989). Evolutionary theories in economics have already been successfully applied to problems of technical change, to the development of new institutions, and to the evolution of means of payment.

For large, slow-growing animals like humans, genetic evolution has a built-in bias towards the long run. Changing the genetic structure of a species requires that characteristics (phenotypes) be selected and accumulated by differential reproductive success. Behaviors learned or acquired during the lifetime of an individual cannot be passed on genetically. Genetic evolution is therefore usually a relatively slow process requiring many generations to significantly alter a species' physical and biological characteristics.

Cultural evolution is potentially much faster. Technical change is perhaps the most important and fastest evolving cultural process. Learned behaviors that are successful, at least in the short term, can be almost immediately spread to other members of the culture and passed on in the oral, written, or video record. The increased speed of adaptation that this process allows has been largely responsible for Homo sapiens' amazing success at appropriating the resources of the planet. Vitousek et al. (1986) estimate that humans now directly control from 25 to $40 \%$ of the total primary production of the planet's biosphere, and this is beginning to have significant effects on the biosphere, including changes in global climate and in the planet's protective ozone shield.

Thus, the costs of this rapid cultural evolution are potentially significant. Like a car that has increased speed, humans are in more danger of running off the road or over a cliff. Cultural evolution lacks the built-in long-run bias of genetic evolution and is susceptible to being led by its hyper-efficient short-run adaptability over a cliff into the abyss.

Another major difference between cultural and genetic evolution may serve as a countervailing bias, however. As Arrow (1962) has pointed out, cultural and economic evolution, unlike genetic evolution, can at least to some extent employ foresight. If society can see the cliff, perhaps it can be avoided.

While market forces drive adaptive mechanisms (Kaitala and Pohjola 1988), the systems that evolve are not necessarily optimal, so the question remains: What external influences are needed and when should they be applied in order to achieve an optimum economic system via evolutionary adaptation? The challenge faced by ecological economic systems modelers is to first apply the models to gain foresight, and then to respond to and manage the system feedbacks in a way that helps avoid any foreseen cliffs (Berkes and Folke 1994). Devising policy instruments and identifying incentives that can translate this foresight into effective modifications of the short-run evolutionary dynamics is the challenge (Costanza 1987).

Evolutionary criteria.-A critical problem in applying the evolutionary paradigm in dynamic models is defining the selection criteria a priori. In its basic form the theory of evolution is circular and descriptive 
(Holling 1987). Those species or cultural institutions or economic activities survive that are the most successful at reproducing themselves. But we only know which ones were more successful after the fact. To use the evolutionary paradigm in modeling, we require a quantitative measure of fitness (or more generally performance) in order to drive the selection process.

Several candidates have been proposed for this function in various systems, ranging from expected economic utility to thermodynamic potential. Thermodynamic potential is interesting as a performance criterion in complex systems because even very simple chemical systems can be seen to evolve complex non-equilibrium structures using this criterion (Prigogine 1972, Nicolis and Prigogine 1977, 1989), and all systems are (at minimum) thermodynamic systems (in addition to their other characteristics) so that thermodynamic constraints and principles are applicable across both ecological and economic systems (Eriksson 1991).

This application of the evolutionary paradigm to thermodynamic systems has led to the development of far-from-equilibrium thermodynamics and the concept of "dissipative structures" (Prigogine 1972). An important research question is to determine the range of applicability of these principles and their appropriate use in modeling ecological economic systems.

Many dissipative structures follow complicated transient motions. Schneider and Kay (1994) propose a way to analyze these chaotic behaviors and note that, "Away from equilibrium, highly ordered stable complex systems can emerge, develop and grow at the expense of more disorder at higher levels in the system's hierarchy." It has been suggested that the integrity of far-from-equilibrium systems has to do with the ability of the system to attain and maintain its (set of) optimum operating point(s) (Kay 1991). The optimum operating point(s) reflect a state where self-organizing thermodynamic forces and disorganizing forces of environmental change are balanced. This idea has been elaborated and described as "evolution at the edge of chaos" by Bak and Chen (1991) and Kauffman and Johnson (1991).

The concept that a system may evolve through a sequence of stable and unstable stages leading to the formation of new structures seems well suited to ecological economic systems. For example, Gallopin (1989) stresses that to understand the processes of economic impoverishment ". . . The focus must necessarily shift from the static concept of poverty to the dynamic processes of impoverishment and sustainable development within a context of permanent change. The dimensions of poverty cannot any longer be reduced to only the economic or material conditions of living; the capacity to respond to changes, and the vulnerability of the social groups and ecological systems to change become central." In a similar fashion Robinson (1991) argues that sustainability calls for maintenance of the dynamic capacity to respond adaptively, which implies that we should focus more on basic natural and social processes, than on the particular forms these processes take at any time. Berkes and Folke (1994) have discussed the capacity to respond to changes in ecological economic systems in terms of institution building, collective actions, cooperation, and social learning. These might be some of the ways to enhance the capacity for resilience (increase the capacity to recover from disturbance) in interconnected ecological-economic systems.

\section{INTEGRATED MODELING AS A CONSENSUS-BUILDING TOOL IN AdAPTIVE MANAGEMENT}

It is not enough for groups of academic "experts" to build integrated models. What is required is a new role for modeling as a tool in building a broad consensus not only across academic disciplines, but also between science and policy. More broadly, this process of stakeholder involvement is a key one to achieving sustainability. Ethicist John Rawls (Rawls 1971, 1987) has argued persuasively that policies that represent an "overlapping consensus" of the interest groups involved in a problem will be fair, and this will result in their also being effective and resilient. Thus, solutions to the problems of sustainability will only be robust (resilient) and effective if they are fair and equitable (the fair distribution criterion mentioned earlier) to all of the interest groups involved, including future generations and other species.

Integrated modeling of large regional systems, from watersheds to continental-scale systems and ultimately to the global scale, requires input from a very broad range of people. We need to see the modeling process as one that involves not only the technical aspects, but also the sociological aspects involved with using the process to help build consensus about the way the system works and which management options are most effective. This consensus needs to extend both across the gulf separating the relevant academic disciplines and across the even broader gulf separating the science and policy communities and the public. Appropriately designed and appropriately used integrated ecologicaleconomic modeling exercises can help to bridge these gulfs.

The process of modeling can (and must) also serve this consensus-building function. It can help to build mutual understanding, solicit input from a broad range of stakeholder groups, and maintain a substantive dialogue between members of these groups. In the process of adaptive management, integrated modeling and consensus building are essential components (Gunderson et al. 1995).

The potential to use modeling as a way to build consensus has been greatly expanded in recent years by the advent of new, much easier-to-use computers and modeling software. As just one example, it is now possible, with graphic, icon-based modeling software 
packages (such as STELLA from High Performance Systems, Inc, Hannover, New Hampshire, USA) to involve a group of relative modeling novices in the construction of relatively complex models, with a few people competent in modeling acting as facilitators. STELLA uses the simple basic model components of stocks, flows, auxiliary variables, and functional connections. The graphic representations of these units are connected and manipulated on the screen to build the basic structure of the model. This process can be transparent to a group when the computer screen in projected onto the wall. Participants can then both follow the model construction process and contribute their knowledge to the process. After the basic model structure is developed, the program requires more detailed decisions about the functional connections between variables. This process is also transparent to the group, using well-designed dialogue boxes, and the potential for both graphic and algebraic input. Once preliminary versions of the model have been constructed, it can be run to develop understanding of its dynamics and sensitivity, to compare its behavior to data for the system, and to help decide where best to put additional effort in improving the model. This can be thought of as an initial "scoping" step that facilitates broad-based input and consensus.

Based on this initial "consensus-building" modeldevelopment stage, which focuses on generalism as described above, it may be appropriate and desirable to move to a more realistic or precise modeling stage. This stage could involve more traditional "experts" and is more concerned with analyzing the details of specific scenarios or policy options. For example, an ongoing long-term integrated modeling study of the Patuxent River watershed in Maryland (Bockstael et al. 1995) has moved into this "policy analysis" stage of model development and use. It is still critical to maintain stakeholder involvement and interaction in this stage with regular workshops and meetings to discuss model progress and results.

While integrated models aimed at realism and precision are large, complex, and loaded with uncertainties of various kinds (Costanza et al. 1990, Groffman and Likens 1994, Bockstael et al. 1995), our abilities to understand, communicate, and deal with these uncertainties are rapidly improving. It is also important to remember that while increasing the resolution and complexity of models increases the amount we can say about a system, it also limits how accurately we can say it. Model predictability tends to fall with increasing resolution due to compounding uncertainties (Costanza and Maxwell 1993). What we are after are models that optimize their "effectiveness" (Costanza and Sklar 1985 ) by choosing an intermediate resolution where the product of predictability and resolution (effectiveness) is maximized.

It is also necessary to place the modeling process within the larger framework of adaptive management
(Holling 1978) if it is to be effective. We need to view the implementation of policy prescriptions in a different, more adaptive way that acknowledges the uncertainty embedded in our models and allows participation by all the various stakeholder groups. "Adaptive management" views regional development policy and management as "experiments," where interventions at several scales are made to achieve understanding and to identify and test policy options (Holling 1978, Walters 1986, Lee 1993, Gunderson et al. 1995). This means that models and policies based on them are not taken as the ultimate answers, but rather as guiding an adaptive experimentation process with the regional system. More emphasis is placed on monitoring and feedback to check and improve the model, rather than using the model to obfuscate and defend a policy that is not corresponding to reality. Continuing stakeholder involvement is essential in adaptive management.

\section{ACKNOWLEDGMENTS}

I would like to thank two anonymous reviewers for helpful comments on earlier drafts. This paper is a synthesis and overview of ideas that are more fully developed in a number of other papers with several co-authors, including Herman Daly, Carl Folke, Lisa Wainger, Richard Norgaard, and KarlGöran Mäler. It contains work funded by a number of projects, including EPA Cooperative Agreement Number 07-5-251963734, titled "Ecological Economic Modeling and Valuation of Ecosystems," Nancy Bockstael and Robert Costanza, Project managers, and the EPA-funded University of Maryland Multiscale Experimental Ecosystem Research Center, Tom Malone, center director.

\section{Literature CiTED}

Allee, W. C., A. E. Emerson, O. Park, T. Park, and K. P. Schmidt. 1949. Principles of animal ecology. Saunders, Philadelphia, Pennsylvania, USA.

Allen, T. F. H., and T. B. Starr. 1982. Hierarchy. University of Chicago Press, Chicago, Illinois, USA.

Andrewartha, H. G., and L. C. Birch. 1954. The distribution and abundance of animals. University of Chicago Press, Chicago, Illinois, USA.

Arrow, K. 1962. The economic implications of learning by doing. Review of Economic Studies. 29:155-173.

Arthur, W. B. 1988. Self-reinforcing mechanisms in economics. Pages 9-31 in P. W. Anderson, K. J. Arrow, and D. Pines, editors. The economy as an evolving complex system. Adisson Wesley, Redwood City, California, USA.

Bak, P., and K. Chen. 1991. Self-organized criticality. Scientific American 264:46.

Barbier, E. B., J. C. Burgess, and C. Folke. 1994. Paradise lost? The ecological economics of biodiversity. Earthscan, London, England.

Berkes, F., and C. Folke. 1994. Investing in cultural capital for sustainable use of natural capital. Pages 128-149 in A. J. Jansson, M. Hammer, C. Folke, and R. Costanza, editors. Investing in natural capital: the ecological economics approach to sustainability. Island Press, Washington, D.C., USA.

Bockstael, N., R. Costanza, I. Strand, W. Boynton, K. Bell, and L. Wainger. 1995. Ecological economic modeling and valuation of ecosystems. Ecological Economics 14:143159.

Boulding, K. E. 1981. Evolutionary economics. Sage, Beverly Hills, California, USA.

Boyd, R., and P. J. Richardson. 1985. Culture and the evo- 
lutionary process. University of Chicago Press, Chicago, Illinois, USA.

Brown, G. M., and J. Roughgarden. 1992. An ecological economy: notes on harvest and growth. Beijer Discussion Paper Series Number 12. Beijer International Institute of Ecological Economics, Stockholm, Sweden.

Brown, G. M., and J. Swierzbinski. 1985. Endangered species, genetic capital and cost-reducing R\&D. Pages 111127 in D. O. Hall, N. Myers, and N. S. Margaris, editors. Economics of ecosystems management. Dr. W. Junk, Dordrecht, The Netherlands.

Clark, C. W. 1976. Mathematical bioeconomics. John Wiley \& Sons, New York, New York, USA.

. 1981. Bioeconomics of the ocean. BioScience 31: 231-237.

- 1985. Bioeconomic modelling and fisheries management. John Wiley \& Sons, New York, New York, USA.

Clark, C. W., and G. R. Munro. 1975. The economics of fishing and modern capital theory: a simplified approach. Journal of Environmental Economics and Management 2: 92-106.

Clark, C. W., and G. R. Munro. 1994. Renewable resources as natural capital: the fishery. Pages 343-361 in A. M. Jansson, M. Hammer, C. Folke, and R. Costanza, editors. Investing in natural capital: the ecological economics approach to sustainability. Island Press, Washington, D.C., USA.

Coats, A. W. 1993. The sociology and professionalization of economics. Routledge, New York, New York, USA.

Common, M., and C. Perrings. 1992. Towards an ecological economics of sustainability. Ecological Economics 6:7-34.

Costanza, R. 1987. Social traps and environmental policy. BioScience 37:407-412.

— , editor. 1991. Ecological economics: the science and management of sustainability. Columbia University Press, New York, New York, USA.

- 1994. Three general policies to achieve sustainability. Pages 392-407 in A. M. Jansson, M. Hammer, C. Folke, and R. Costanza, editors. Investing in natural capital: the ecological economics approach to sustainability. Island Press, Washington, D.C., USA.

Costanza, R., and L. Cornwell. 1992. The 4P approach to dealing with scientific uncertainty. Environment 34:12-20.

Costanza, R., and H. E. Daly. 1987. Toward an ecological economics. Ecological Modelling 38:1-7.

Costanza, R., and H. E. Daly. 1992. Natural capital and sustainable development. Conservation Biology 6:37-46.

Costanza, R., and T. Maxwell. 1993. Resolution and predictability: an approach to the scaling problem. Landscape Ecology 9:47-57.

Costanza, R., R. Norgaard, J. Cumberland, H. Daly, and R. Goodland. 1997. Introduction to ecological economics. St. Lucie Press, Delray Beach, Florida, USA, in press.

Costanza, R., B. Norton, and B. J. Haskell, editors. 1992. Ecosystem health: new goals for environmental management. Island Press, Washington, D.C., USA.

Costanza, R., and F. H. Sklar. 1985. Articulation, accuracy, and effectiveness of mathematical models: a review of freshwater wetland applications. Ecological Modeling 27: 45-68.

Costanza, R., F. H. Sklar, and M. L. White. 1990. Modeling coastal landscape dynamics. BioScience 40:91-107.

d'Arge, R. C. 1994. Sustenance and sustainability: how can we preserve and consume without major conflict. Pages 113-127 in A. M. Jansson, M. Hammer, C. Folke, and R. Costanza, editors. Investing in natural capital: the ecological economics approach to sustainability. Island Press, Washington, D.C., USA

Day, R. H. 1989. Dynamical systems, adaptation and economic evolution. Modeling Research Group (MRG) Work- ing Paper Number M8908. Department of Economics, University of Southern California, Los Angeles, California, USA.

Day, R. H., and T. Groves, editors. 1975. Adaptive economic models. Academic Press, New York, New York, USA.

Debreu, G. 1974. Excess demand functions. Journal of Mathematical Economics 1:15-23.

Duchin, F. 1988. Analyzing structural change in the economy. Pages 113-128 in M. Ciaschini, editor. Input-output analysis: current developments. Chapman \& Hall, London, England.

1992. Industrial input-output analysis: implications for industrial ecology. Proceedings of the National Academy of Sciences (USA) 89:851-855.

Dunlap, R. E. 1980. Paradigmatic change in social science: from human exemptionalism to an ecological paradigm. American Behavioral Science 24:5-14.

Eriksson, K-E. 1991. Physical foundations of ecological economics. Pages 186-196 in L. O. Hansson and B. Jungen, editors. Human responsibility and global change. University of Göteborg Press, Göteborg, Sweden.

Fitz, H. C., E. B. DeBellevue, R. Costanza, R. Boumann, T. Maxwell, and L. Wainger. 1996. Development of a general ecosystem model (GEM) for a range of scales and ecosystems. Ecological Modelling, 88:263-297.

Gallopin, G. C. 1989. Global impoverishment, sustainable development and the environment: a conceptual approach. International Social Science Journal 121:375-397.

Golley, F. B. 1994. Rebuilding a humane and ethical decision system for investing in natural capital. Pages 169-178 in A. M. Jansson, M. Hammer, C. Folke, and R. Costanza, editors. Investing in natural capital: the ecological economics approach to sustainability. Island Press, Washington, D.C., USA.

Groffman, P. M., and G. E. Likens, editors. 1994. Integrated regional models: interactions between humans and their environment. Chapman \& Hall, New York, New York, USA.

Gunderson, L., C. S. Holling, and S. Light, editors. 1995. Barriers and bridges to the renewal of ecosystems and institutions. Columbia University Press, New York, New York, USA.

Günther, F., and C. Folke. 1993. Characteristics of nested living systems. Journal of Biological Systems 1:257-274.

Hammer, M., A. M. Jansson, and B-O. Jansson. 1993. Diversity change and sustainability: implications for fisheries. Ambio 22:97-105.

Hannon, B., and C. Joiris. 1987. A seasonal analysis of the southern North Sea ecosystem. Ecology 70:1916-1934.

Hardesty, D. L. 1977. Ecological anthropology. John Wiley \& Sons, New York, New York, USA.

Harris, M. 1979. Cultural materialism: the struggle for a science of culture. Random House, New York, New York, USA.

Holland, J. H., and J. H. Miller. 1991. Artificial adaptive agents in economic theory. American Economic Review 81:365-370.

Holling, C. S. 1964. The analysis of complex population processes. Canadian Entomologist 96:335-347.

. 1966. The functional response of invertebrate predators to prey density. Memoirs of the Entomological Society of Canada 48.

, editor. 1978. Adaptive environmental assessment and management. John Wiley \& Sons, London, England.

. 1987. Simplifying the complex: the paradigms of ecological function and structure. European Journal of Operational Research 30:139-146.

- 1992. Cross-scale morphology, geometry, and dynamics of ecosystems. Ecological Monographs 62:447502. 
1994. New science and new investments for a sustainable biosphere. Pages 57-73 in A. M. Jansson, M. Hammer, C. Folke, and R. Costanza, editors. Investing in natural capital: the ecological economics approach to sustainability. Island Press, Washington, D.C., USA.

Jansson, A. M., M. Hammer, C. Folke, and R. Costanza, editors. 1994. Investing in natural capital: the ecological economics approach to sustainability. Island Press, Washington, D.C., USA.

Jansson, A. M., and B. O. Jansson. 1994. Ecosystem properties as a basis for sustainability. Pages 74-91 in A. M. Jansson, M. Hammer, C. Folke, and R. Costanza, editors. Investing in natural capital: the ecological economics approach to sustainability. Island Press, Washington, D.C., USA.

Kaitala, V., and M. Pohjola. 1988. Optimal recovery of a shared resource stock: a differential game model with efficient memory equilibria. Natural Resource Modeling 3: 91-119.

Kauffman, S. A., and S. Johnson. 1991. Coevolution to the edge of chaos: coupled fitness landscapes, poised states, and coevolutionary avalanches. Journal of Theoretical Biology 149:467-505.

Kay, J. J. 1991. A nonequilibrium thermodynamic framework for discussing ecosystem integrity. Environmental Management 15:483-495.

Keynes, J. M. 1936. General theory of employment, interest and money. Harcourt Brace, London, England.

Klein, L. R. 1971. Forecasting and policy evaluation using large-scale econometric models: the state of the art. In M. D. Intriligator, editor. Frontiers of quantitative economics. North-Holland, Amersterdam, The Netherlands.

Krishnan, R., J. M. Harris, and N. Goodwin, editors. 1995. A survey of ecological economics. Island Press, Washington, D.C., USA.

Lee, K. 1993. Compass and the gyroscope. Island Press, Washington, D.C., USA.

Levins, R. 1966. The strategy of model building in population biology. American Scientist 54:421-431.

Lindgren, K. 1991. Evolutionary phenomena in simple dynamics. Pages 295-312 in C. G. Langton, C. Taylor, J. D. Farmer, and S. Rasmussen, editors. Artificial life, SFI studies in the sciences of complexity. Volume X. AddisonWesley, London, England.

Lines, M. 1989. Environmental noise and nonlinear models: a simple macroeconomic example. Economic Notes 19: 376-394.

-1990. Stochastic stability considerations: a nonlinear example. International Review of Economics and Business 37:219-233.

Lucas, R. E. 1975. An equilibrium model of the business cycle. Journal of Political Economy 83:1113-1145.

Ludwig, D., R. Hilborn, and C. Walters. 1993. Uncertainty, resource exploitation, and conservation: lessons from history. Science 260:17,36.

Mäler, K-G. 1991. National accounts and environmental resources. Environmental and Resource Economics 1:1-15.

Martinez-Alier, J. 1987. Ecological economics: energy, environment, and society. Blackwell, Oxford, England.

Maxwell, T., and R. Costanza. 1993. An approach to modeling the dynamics of evolutionary self organization. Ecological Modeling 69:149-161.

McIntosh, R. P. 1985. The background of ecology: concept and theory. Cambridge University Press, Cambridge, England.

Meadows, D. H., D. L. Meadows, J. Randers, and W. W. Behrens. 1972. The limits to growth. Universe, New York, New York, USA.

Nicolis, G., and I. Prigogine. 1977. Self organization in non- equilibrium systems. John Wiley \& Sons, New York, New York, USA.

Nicolis, G., and I. Prigogine. 1989. Exploring complexity. W. H. Freeman, New York, New York, USA.

Norgaard, R. B. 1989. The case for methodological pluralism. Ecological Economics 1:37-57.

Norton, B. G., and R. E. Ulanowicz. 1992. Scale and biodiversity policy: a hierarchical approach. Ambio 21:244249.

Odum, E. P. 1971. Fundamentals of ecology. Third edition. W. B. Saunders, Philadelphia, Pennsylvania, USA.

Odum, H. T. 1971. Environment, power, and society. John Wiley \& Sons, New York, New York, USA.

O'Neill, R. V., D. L. DeAngelis, J. B. Waide, and T. F. H. Allen. 1986. A hierarchical concept of ecosystems. Princeton University Press, Princeton, New Jersey, USA.

O'Neill, R. V., A. R. Johnson, and A. W. King. 1989. A hierarchical framework for the analysis of scale. Landscape Ecology 3:193-205.

O'Neill, R. V., and B. Rust. 1979. Aggregation error in ecological models. Ecological Modeling 7:91-105.

Peet, John. 1992. Energy and the ecological economics of sustainability. Island Press, Washington, D.C., USA.

Perrings, C. A. 1994. Biotic diversity, sustainable development, and natural capital. Pages 92-112 in A. M. Jansson, M. Hammer, C. Folke, and R. Costanza; editors. Investing in natural capital: the ecological economics approach to sustainability. Island Press, Washington, D.C., USA.

Prigogine, I. 1972. Thermodynamics of evolution. Physics Today 23:23-28.

Rapport, D. J. 1993. Book review of Man, Nature, and Technology. Ecological Economics 7:79-83.

Rastetter, E. B., A. W. King, B. J. Cosby, G. M. Hornberger, R. V. O'Neill, and J. E. Hobbie. 1992. Aggregating finescale ecological knowledge to model coarser-scale attributes of ecosystems. Ecological Applications 2:55-70.

Rawls, J. 1971. A theory of justice. Oxford University Press, Oxford, England.

- 1987. The idea of an overlapping consensus. Oxford Journal of Legal Studies 7:1-25.

Robinson, J. B. 1991. Modelling the interactions between human and natural systems. International Social Science Journal 130:629-647.

- 1992. Of maps and territories: the use and abuse of socio-economic modelling in support of decision-making. Technological Forecasting and Social Change 42:147-164.

Rosser, J. B. 1991. From catastrophe to chaos: a general theory of economic discontinuities. Kluwer, Amsterdam, The Netherlands.

- 1992. The dialogue between the economic and ecologic theories of evolution. Journal of Economic Behavior and Organization 17:195-215.

Schneider, E. D., and J. J. Kay. 1994. Life as a manifestation of the second law of thermodynamics. International Journal of Mathematical and Computer Modelling 19:25-48.

Shugart, H. H. 1989. The role of ecological models in longterm ecological studies. Pages 90-109 in G. E. Likens, editor. Long-term studies in ecology: approaches and alternatives. Springer-Verlag, New York, New York, USA.

Solow, R. M. 1956. A contribution to the theory of economic growth. Quarterly Journal of Economics 70:65-94.

Sonnenschein, H. 1974. Market excess demand functions. Econometrica 40:549-563.

Taub, F. B. 1987. Indicators of change in natural and humanimpacted ecosystems: status. Pages 115-144 in S. Draggan, J. J. Cohrssen, and R. E. Morrison, editors. Preserving ecological systems: the agenda for long-term research and development. Praeger, New York, New York, USA. 
ment and testing. Pages 47-92 in A. Boudou and F. Ribeyre, editors. Aquatic ecotoxicology: fundamental concepts and methodologies. Volume II. CRC Press, Boca Raton, Florida, USA.

Turner, R. K., P. Doktor, and N. Adger. 1994. Sea-level rise and coastal wetlands in the U.K.: mitigation strategies for sustainable management. Pages 266-290 in A. M. Jansson, M. Hammer, C. Folke, and R. Costanza, editors. Investing in natural capital: the ecological economics approach to sustainability. Island Press, Washington, D.C., USA.

Viederman, S. 1994. Public policy: challenge to ecological economics. Pages 467-490 in A. M. Jansson, M. Hammer, C. Folke, and R. Costanza, editors. Investing in natural capital: the ecological economics approach to sustainability. Island Press, Washington, D.C., USA.

Vitousek, P. M., P. R. Ehrlich, A. H. Ehrlich, and P. A. Matson.
1986. Human appropriation of the products of photosynthesis. BioScience 36:368-373.

von Bertalanffy, L. 1968. General system theory: foundations, development, applications. George Braziller, New York, New York, USA.

Walters, C. J. 1986. Adaptive management of renewable resources. McGraw-Hill, New York, New York, USA.

Wroblewski, J. S., and E. E. Hofmann. 1989. U.S. interdisciplinary modeling studies of coastal-offshore exchange processes: past and future. Progress in Oceanography 23: 65-99.

Wulff, F., and R. E. Ulanowicz. 1989. A comparative anatomy of the Baltic Sea and Chesapeake Bay ecosystems. Pages 232-256 in F. Wulff, J. G. Field, and K. H. Mann, editors. Network analysis of marine ecology: methods and applications. Coastal and estuarine studies series. SpringerVerlag, Heidelberg, Germany. 